\title{
Metabolic rates in hatchery-reared European lobster juveniles (Homarus gammarus L.)
}

\begin{abstract}
The existing information on the metabolism in European lobster (Homarus gammarus) is sparse. However, dimensioning of intensive systems for commercial production of lobster in recirculating aquaculture systems (RAS) requires adequate information in order to optimise financial calculations and profit margins. Thus, a lack of available data, especially regarding oxygen consumption and ammonia excretion, hampers development and commercialisation of lobster aquaculture. During 2010 and 2013, respiration and excretion rates in juvenile lobsters ranging from 0.06 to $208 \mathrm{~g}$ were recorded in a respirometer. These tests aimed to obtain data of standard metabolism in lobster at normal activity and optimum temperature $\left(20 \pm 1^{\circ} \mathrm{C}\right)$. The metabolic rate in fed juveniles $<2 \mathrm{~g}$ varied from 1.2 to $14.3 \mathrm{mg}$ $\mathrm{O} 2 / \mathrm{kg}$ min. In the larger juveniles and adults, the metabolic rate was less variable ranging from 1.1 to $3.1 \mathrm{mg} \mathrm{O} 2 / \mathrm{kg} \mathrm{min}$. The respiration rate in unfed lobsters was relatively stable, varying from 0.8 to $2.4 \mathrm{mg} \mathrm{O} 2 / \mathrm{kg}$ min. The excretion rate was likewise larger in the smaller juveniles with a mean of $0.51 \mathrm{mg} \mathrm{TAN} / \mathrm{kg} / \mathrm{min}$ compared with the largest individuals of 0.07 . This article briefly describes the two respirometer tests performed in order to improve the financial stipulations and reduce the economic risk in a critical stage of development.
\end{abstract}

Volume 5 Issue 5 - 2017

\author{
Asbjorn Drengstig,' Asbjorn Bergheim, ${ }^{2}$ Stig \\ Westerlund, ${ }^{2}$ Ann Lisbeth Agnalt ${ }^{3}$ \\ 'Norwegian Lobster Farm AS, Norway \\ ${ }^{2}$ IRIS-International Research Institute of Stavanger, Norway \\ ${ }^{3}$ Institute of Marine Research, Norway
}

Correspondence: Asbjørn Drengstig, Norwegian Lobster Farm AS, Norway, Tel: +47 9019673।; Fax: +47 5132590।; Email asbjorn.drengstig@lyse.net

Received: April 29, 2017 | Published: May 18, 2017

\section{Introduction}

European lobster (Homarus gammarus) is a high value species where landings are low and commercial farming has yet to be established. On the other hand, European lobster is identified as one of the most promising aquaculture species, due to very high prospected profit margins (e.g. Anon. 2003; Anon. 2005; Anon. 2003)., ${ }^{1,2}$ Moreover there is a huge gap between supply and demand, resulting in stable and high consumer demand and market price in all market segments around the globe. During the last decade, several breaktroughs were made in the progress of developing lobster aquaculture. These include recirculation of seawater and development of lowcost industrial automation technology making it possible to meet the particular demands of lobster farming. ${ }^{3-5}$ Based on the promising potential for farming lobsters, the European industry joined forces and established the network association the European Lobster Center of Excellence (ELCE - www.elce-net.org). ELCE has members from Norway, Denmark, Sweden, Italy, Spain, Iceland and UK. The main aim with the association is to develop business cases enabling multiple establishments in the EU implementing state-of-the-art land-based culture systems for European lobster. The network also facilitates R\&D facilities where new aquapreneurs can do preliminary testing of new technologies for on-shore lobster farming. In order to succeed with land-based farming, major prerequisites such as feed utilisation/ feed conversion ratio (FCR), oxygen consumption, excretory values on carbon dioxide (CO2) and total ammonia (TAN) must be acquired. Currently, knowledge is lacking on among others respiration and excretion rates in European lobster. This is urgently needed for dimensioning criteria for water treatment units in Recirculating Aquaculture Systems (RAS). During the last years, Norwegian Lobster Farm AS (NLF) has jointly with International Research Institute of Stavanger (IRIS) and Institute of Marine Research (IMR) conducted preliminary studies aiming to determine respiration and excretion rates in European lobster. These studies were made in order to determine the range of optimal and critical/threshold levels of key water quality parameters for European lobsters.

\section{Materials and methods}

All juveniles were hatchery-reared based on genetically tagged brood-stock. In 2010, juvenile European lobster from NLF's commercial RAS factory on Kvitsøy were tested, whereas in the 2013 the juveniles were from Institute of Marine Research, research station in Parisvatnet. The sizes ranged from recently settled stage III larvae at 0.02 gram (corresponding to $5 \mathrm{~mm}$ carapace length, CL) to juveniles/subadults at 208 gram (corresponding to CL of $70 \mathrm{~mm}$ ). CL was recorded with a vernier caliper from the base of the eye socket to the posterior-medial edge of the cephalothorax. Wet body weight was recorded to nearest $0.1 \mathrm{~g}$. In both years, the IRIS laboratory performed the tests according to standardised procedures which can be replicated (Figure 1). The lobsters were kept separately throughout the process. In order to reduce the stress level caused by handling and transport, the animals were acclimatised for 7 days upon experimental start. The animals were fed commercially prepared feed (tailor made for lobster by NLF), one pellet every three days according to the production protocols developed by NLF. No feeding took place throughout the respirometer stay. A group of lobster were also analysed in nonfed condition. For these individuals, feeding ended 7 days prior to experimental start.

For the larger lobsters, two identical respirometers of $3.9 \mathrm{~L}$ were used with online dissolved oxygen/temperature sensors (Oxygen Optode/Temperature Sensor 3830/3835 from Aanderaa Data Instruments). A program allows for table and/or graphical forms of the results. The respirometer chambers differed a bit in size depending on the lobster size. At the start of each test, DO concentration was 240 $265 \mu \mathrm{M}$ or $90-100 \%$ of saturation level at $19.5-21.0^{\circ} \mathrm{C}$ and $>32 \%$ salinity. All calculations of specific oxygen consumption were based on the DO concentration reduction rate from start level to $200 \mu \mathrm{M}$ equal to $70-75 \%$ of saturation level. This procedure was introduced to avoid any extra stress due to hypoxia. Sampling for total ammonia analysis (TAN) was performed at the end of each test. The samples were added acid for conservation and sent to the Norwegian Institute for Water Research (NIVA) for further analysis. On several occasions 
this sampling took place at lower DO concentrations than $200 \mu \mathrm{M}$ and therefore more and less affected by stressful conditions $\mathrm{pH}$ was measured at the same time and levels below 7.9 are not considered representing routine conditions.

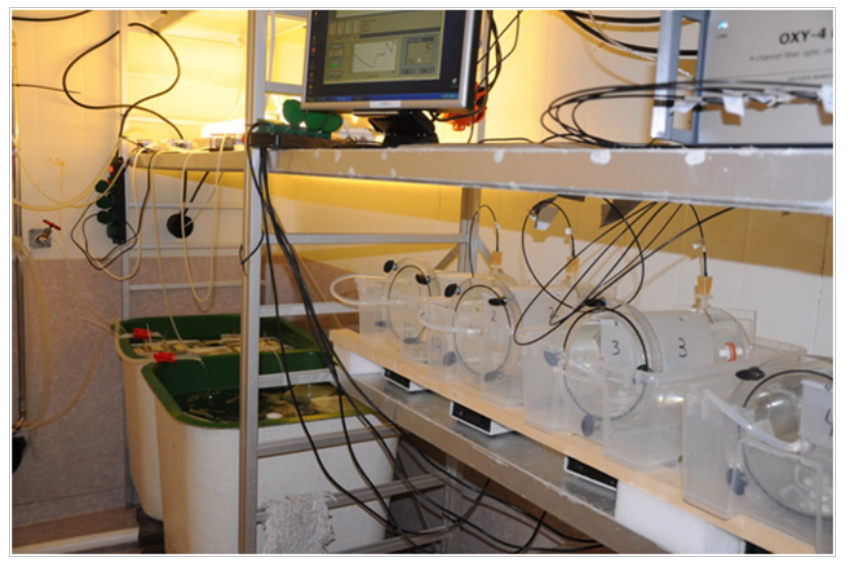

Figure I Test facilities with running respirometers and logging of data.

\section{Results}

Total oxygen consumption in the individuals from 2010 and 2013 showed very similar results (Figure 2), with higher variation in the smaller individuals compares with the larger ones. In the experiment where the juveniles were fed, the oxygen consumption in lobster $<$ $2 \mathrm{~g}$ varied from 1.2 to $14.3 \mathrm{mg} \mathrm{O} / \mathrm{kg} \mathrm{x}$ min. In the larger juveniles and subadults the consumption rate was less variable, from 1.1 to 3.1 $\mathrm{mg} \mathrm{O} 2 / \mathrm{kg}$ x min. In un-fed lobster, the metabolic rate was relatively stable, varying from 0.8 to $2.4 \mathrm{mg} \mathrm{O} / \mathrm{kg} \times \mathrm{min}$. Carbon dioxide can be a limiting parameter, especially when pure oxygen is added in order to sustain intensive production $(>40 \mathrm{~kg} / \mathrm{m} 3)$. The measured $\mathrm{CO} 2$-production was on average 1.5 - 2 times the corresponding $\mathrm{O} 2$ consumption.

Excretion rates were measured, and the ammonia analyses indicate, as expected, a higher specific excretion rate in terms of $\mathrm{mg}$ TAN $/ \mathrm{kg} \mathrm{x}$ min in juveniles compared to the larger-by size individuals (Table 1). However, replicate sampling of the same size groups demonstrated considerable fluctuation from one test situation to another. Increased excretion rate in the largest animals (120 - $210 \mathrm{~g})$ was positively correlated with increased oxygen consumption in the same individuals (Figure 3).

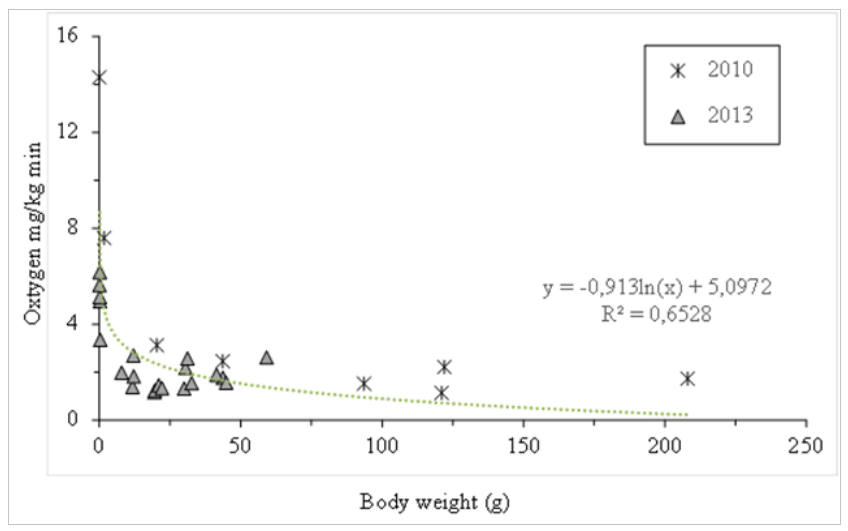

Figure 2 Mean oxygen consumption in hatchery-reared European lobster (Homarus gammarus), ranging in size from larvae to adults. The experiments were run in 2010 and 2013.
Table I Excretion rates measured as mg total ammonia (TAN) per $\mathrm{kg}$ per minute in European lobster (Homarus gammarus) in three size ranges

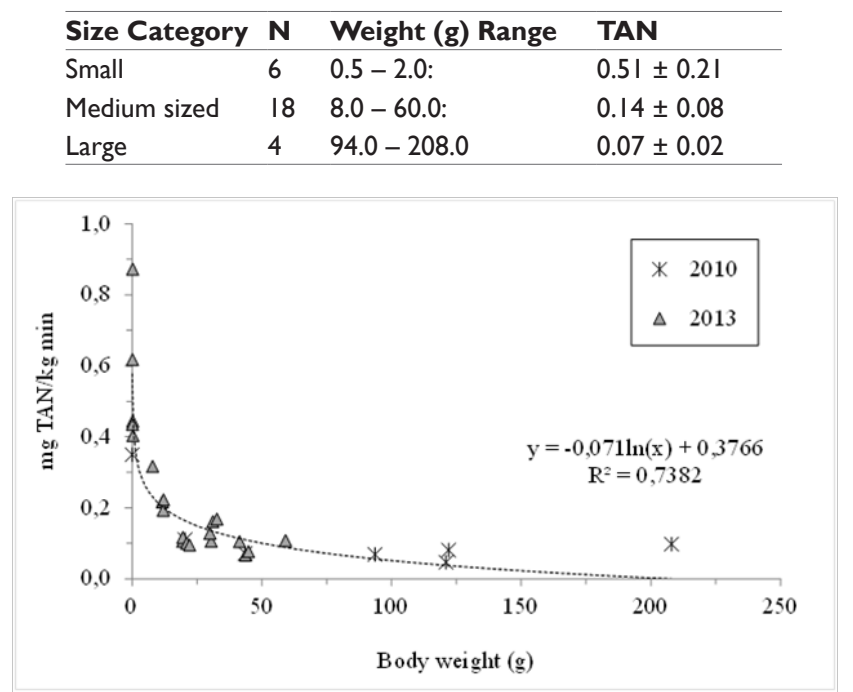

Figure 3 Excretion measured in mg total ammonia (TAN) per $\mathrm{kg}$ per minute in hatchery-reared European lobster (Homarus gammarus) ranging in size from larvae to adults. The experiments were run in 2010 and 2013.

\section{Discussion}

The large individual variability in oxygen consumption at various sizes demonstrates rapid adaptability to new conditions. Typical stress influenced respiration rate seems to be approximately twice the standard rate. The standard rate of European lobster within the size interval $230-600 \mathrm{~g}$ was found to be $0.73 \mathrm{mg} \mathrm{O} 2 / \mathrm{kg} \mathrm{x}$ min at $20^{\circ} \mathrm{C}^{6}$ i.e. about half of the lowest rate found in this study for lobster of $208 \mathrm{~g}$. The oxygen consumption ranges were large, 1:8 to 1:3 within the same size groups, and the fluctuations may be due to diurnal rhythm and peak at feeding. The measured CO2-production was on average 1.5-2 times the corresponding $\mathrm{O} 2$-consumption. As in other aquatic animals with similar activity levels, the oxygen uptake is closely linked with the oxygen demand and will vary according to physiological state, behavioural status, activity level and changes in environmental factors as e.g. temperature. ${ }^{7}$ One obvious physiological state in lobster is moulting. Two individuals moulted just before or during the respiration experiment in 2013 (nr.2; 31.2 gr and nr. 19; 59.2 gr), and in fact the oxygen consumption was slightly in the upper range.

Some of the lobsters during the 2010 experiment were probably temporarily stressed, despite the acclimatisation period of 7 days, as peak rates higher than $14.3 \mathrm{mg} / \mathrm{kg}$ x min were recorded. However, such peak rates were always recorded during the first phase of experiment, and could therefore be due to the introduction to the respiration chamber. In addition, several of the adults, i.e. lobsters $>94$ gram also seemed to suffer from stress in the respirometer, probably due to the small size of the chamber.

The studies indicated strongly fluctuating oxygen consumption in lobster of different size at $20 \pm 1^{\circ} \mathrm{C}$. The large variability in oxygen consumption at various sizes also demonstrated rapid adaptability to new conditions. Stress influenced respiration rates to increase to approximately twice the standard rates. Ammonia analyses indicated, as expected, a higher specific excretion rate in terms of mg TAN/ $\mathrm{kg} \mathrm{x} \mathrm{min} \mathrm{in} \mathrm{juveniles} \mathrm{compared} \mathrm{with} \mathrm{sub} \mathrm{adults.} \mathrm{However,} \mathrm{replicate}$ sampling of the same size groups demonstrated considerable fluctuation from one test situation to another. Increased excretion rate 
in the larger animals was positively correlated with increased oxygen consumption..$^{8-26}$

\section{Conclusion}

Based on the economic importance of metabolism data, priority is given to detect critical water quality values for dimensioning of technical equipment in order to sustain a healthy environment for lobsters farmed in RAS. Moreover, such data is important to improve growth performance, survival and feed conversion ratio (FCR) in RAS in order to increase the turn-over and successful commercialization for the industry.

\section{Acknowledgments}

None.

\section{Conflicts of interest}

None

\section{References}

1. Drengstig A, Drengstig T, Agnalt A-L, et al. Utvikling av metoder for stabil produksjon av hummeryngel med gode vekstegenskaper 2009;pp.42.

2. Drengstig A, Bergheim A. Single cage technology for on-growing of lobster in RAS. Abstract and oral presentation, Progress in Marine Recirculating Aquaculture Systems. World Aquaculture Society, San Diego, USA, 2010;1-5.

3. Nicosia F, Lavalli K. Homarid lobster hatcheries: Their history and role in research, management, and aquaculture. Marine Fisheries Review. 1999;61(2):1-57.

4. Kristiansen TS, Drengstig A, Bergheim A, et al. Development of intensive farming methods for the European lobster (Homarus gammarus L.) in recirculated seawater. Results from experiments conducted at Kvitsøy Lobster Hatchery from 2000 to 2004. Institute of Marine Research. 2004;pp.52.

5. Drengstig A, Bergheim A. A pilot RAS for commercial production of European lobster. Aquacultural Engineering Society Proceedings VII, pp. 178-186. AES Fifth Issues Forum, Roanoke, Virginia, USA 2010b;16-20

6. Whiteley NM, Al-Wassia AH, Taulor EW. The effect of temperature, aerial exposure and disturbance on oxygen consumption in the lobster, Homarus gammarus L. Mar Behav Physio. 1990;17:213-222.

7. McMahon BR. The physiology of gas exchange, circulation, ion regulation, and nitrogenous excretion: An integrative approach, pp. 497517. In: Factor JR (Eds.), Biology of the lobster Homarus americanus, Academic Press, USA. 1995;PP.528.

8. Agnalt AL. Stock enhancement of European lobster (Homaru gammarus) in Norway; Comparisons of reproduction, growth and movement between wild and cultured lobster. Dr. scient. thesis, Department of Biology, University of Bergen, Norway. 2008

9. Alabaster JS, Lloyd R. Water Quality Criteria for Freshwater Fish. (2nd edn), FAO, Butterwords, London. 1982;pp.361.

10. Aiken DE, Waddy SL. Aquaculture. In: Factor JR (Ed.), Biology of the lobster Homarus americanus. Academic Press, Inc, USA. 1995pp.153175.
11. Beard TW McGregor D. Storage and care of live lobster. Laboratory leaflet number 66 (revised). Cefas, UK. 2004.

12. Beard TW, Richards PR, Wickins JF. The techniques and practicability of year-round production of lobsters, Homarus gammarus (L.), in laboratory recirculation systems. Fisheries Research Technical Report, No. 79, Lowestoft, UK. 1985;pp.22.

13. Crear BJ, Forteath GNR. Feeding rate has the largest effect on the ammonia excretion rate of the southern rock lobster, Jasus edwardslii, and the western rock lobster, Panulirus cygnus. Aquacultural Engineering. 2002;26:239-250.

14. Coffelt RJ, Wikman-Coffelt J. Lobsters: One million One Pounders per Year. Aquacultural Engineering. 1985;4:51-58.

15. D'Abramo LR, Conklin DE. Lobster aquaculture. In: Huner, J., Brown, E.E. (Eds.), Crustacean and mollusc aquaculture in the USA. AVI Publ. Co., Westport, USA. 1985;pp.159-201.

16. Drengstig ATS, Kristiansen A, Bergheim T, et al. It does matter if they are black or white! Quantification of the minimum required level of astaxanthine to ensure natural pigmentation in the European lobster, pp 168-169. Extended abstract and Poster presentation. EAS special publication No. 33. August 2003. Trondheim, Norway. 2003;408.pp.

17. Drengstig A, Agnalt AL, Jørstad K. Genetic mapping to improve growth performance, survival and feed conversion ratio (FCR) for on-growing of European lobster in Recirculating Aquaculture Systems (RAS). Proceeding 9th International Conference and Workshop on Lobster Biology and Management, Bergen, Norway. 2011;pp.19-23.

18. Estrella BT. Techniques for live storage and shipping of American lobster. Technical Report TR-8, 18. Division of Marine Fisheries, Massachusetts. 2002.

19. Factor JR. Biology of the lobster Homarus americanus, Academic Press, New York, USA. 1995;pp.528

20. Grimsen S, Jaques RN, Erenst V, et al. Aspects of automation in a lobster farming plant. Modelling, identification and control. 1987;8(1):61-68.

21. Hamelo JS. Investigation of respiration rates of European lobster (Homarus gammarus) in land-based, lobster farming system. Master thesis, Univ. of Stavanger, Norway. 2006;pp.86.

22. Jacklin M, Combes J. The good Practice Guide to Handling and Storing Live Crustacea. 2007.

23. Richards PR. Some aspects of growth and behaviour in the juvenile lobster Homarus gammarus (Linnaeus). PhD Thesis University of Wales, Bangor, Great Britain. 1981;pp.209.

24. Timmons MB, Losordo JG. Aquaculture water reuse systems: engineering design and management. Elsevier, USA. 1994.

25. Van Olst JC, Carlberg JM, Hughes JT. The biology and management of lobsters, pp. 333 -384. In Cobbs JS \& Phillips, BF (Eds.), Aquaculture, Vol. II Academic Press, USA. 1980;pp.468.

26. Waddy SL. Farming the Homarid Lobsters: State of the Art. World Aquaculture. 1988;19(4):63-71.

27. Wickins JF, Beard TW. Variability in size at moult among individual broods of cultured juvenile lobsters. Aquaculture and Fisheries Management. 1991;22(4):481-489.

28. Wickins JF, Lee DO. Crustacean Farming - Ranching and Culture. Blackwell Science, USA. 2002;pp.446. 